\title{
Naus frágeis e novos paradigmas em literatura e educação
}

\author{
Maria Zilda da Cunha*
}

\section{Resumo}

O século XX assistiu a quebra de referências que ancoravam o mundo social, a transição paradigmática demandou olhar em revista das questóes relacionadas ao homem, sociedade, ciência, arte. Nessa perspectiva traçamos o objetivo deste trabalho: refletir acerca da Literatura Infantil, enquanto fenômeno que se constitui na tensão dialética - Literatura/ Educação. Focamos dois momentos da história da civilização ocidental: o da associação da literatura ao processo educacional, com a inscrição da criança na sociedade, e a contemporaneidade, época em que a literatura infantil revigora o jogo literário, redimensionando processos de formação dos jovens leitores. As articulaçôes aqui presentes constituem sínteses do percurso de docência e pesquisa na USP em Estudos Comparados e Literatura Infantil/Juvenil. Investigação que aprofunda estudos do nosso mestrado e doutorado sobre a formação do pensamento moderno, a dinâmica de construção de conceitos que engendram a práxis educativa e as céleres transformaçóes que motivam releituras. Dentre estas, a do problema da escola em razão de um novo leitor que opera atos de leitura no interfluxo de redes virtuais, com múltiplos códigos, linguagens, e franco acesso à complexidade das questóes sociais. As novas geraçóes vivenciam a mudança paradigmática intensamente, motivo pelo qual a Educação não pode se distanciar dos questionamentos que envolvem as rápidas transformaçóes. Sinalizamos com obra de Ângela Lago (2006) como criativamente a literatura contemporânea para crianças e jovens reflete a complexidade que vivemos, constituindo-se em forte aliada à educação para o acesso ao conhecimento do real e a possibilidade de adoção de uma práxis mais crítica.

Palavras-chave: Paradigma. Educação. Literatura infantil.

* Doutora em Estudos Comparados de Literaturas de Língua Portuguesa pela Universidade de Sáo Paulo - USP. Professora de Literatura Infantil e Juvenil na Universidade de São Paulo nos cursos de graduação e pós-graduação em Letras. 


\section{Educação, criança e Literatura Infantil}

Educação e Literatura constituem duas áreas do saber absolutamente intrincadas, cujas relaçóes aparecem em contextos e momentos distintos da história humana. Nos limites deste trabalho, não se pretende, seguramente, deslindar a complexidade dos aspectos que as relacionam nas várias culturas civilizatórias, nem nas diversas formas de sociedade. Tem-se por objetivo uma breve reflexão acerca do modo como a denominada Literatura Infantil emerge, edifica-se sob a égide da dialética educação e literatura, em dois momentos na história da civilização ocidental: meados do século XVIII e a contemporaneidade.

Como ponto de partida, é possível lembrar que uma ideia específica de educação para crianças, e seu trato com a literatura, faz parte integrante do paradigma da modernidade. A palavra criança, embora extremamente usada nos mais antigos documentos, até aproximadamente o século XVIII, não possuía o significado que a ela atualmente se atribui. A inscrição da criança na sociedade, segundo Ariés (1981), ocorre nos primórdios da Idade Moderna.

Se as "paideias antigas" deixaram vestígios sobre rituais de passagem em algumas fases de vida, a noção das idades, no entanto, era extremamente diferente da que, hoje, é possível imaginar. Ariés (1981), tomando como referência a sociedade medieval, explica que a ideia da particularidade infantil, que distingue a criança do adulto não existia. $\mathrm{O}$ mencionado teórico refere-se à gestação de um "sentimento novo" a respeito da criança que a arte, a iconografia e a religiăo do século IV procuravam exprimir. $\mathrm{O}$ autor explica tratar-se de um sentido que se atribuiu à particularidade de crianças de tenra idade que, pela graça e ingenuidade, tornam-se fonte de distração e relaxamento para o adulto. Esse sentimento provoca severas críticas no final do século XVI e, sobretudo, no século XVII.

Foi entre os escolásticos, moralistas e educadores do século XVII que se deu início a um novo e "autêntico" sentimento de infância, pois eles, recusando-se a considerar as crianças como "brinquedos encantadores", passam a vê-las como "frágeis criaturas de Deus". Tal noção baseia-se nas proposiçóes: das criaturas de Deus, o homem (em seu estágio adulto e dotado de racionalidade) é o mais perfeito; as crianças são frágeis criaturas de Deus, ainda imperfeitas; as crianças devem ser preparadas (controladas) pelo adulto para tornarem homens, com efetivo uso da razão. A preocupação, dessa forma, passa a ser a de educá-las, para torná-las pessoas honradas, probas e homens racionais (ARIÉS, 1981). 
Essa espécie de conhecimento liga-se a outro acontecimento importante do século XVIII, a emergência de uma nova noção de família. Essa instituição começou a organizar-se em torno da criança, que passa a ser objeto de preocupação de teóricos desse século e dos seguintes.

Assim, o infante passa a não conviver com práticas misturadas aos adultos e transferem-se para a escola as responsabilidades do ensino, da disciplina, da aprendizagem como meios de educação. Tal separação deve ser interpretada como uma das faces do grande movimento de moralização dos homens, promovido pelos reformadores católicos e protestantes ligados à Igreja e às leis do Estado (ARIÉS, 1981). Essa chamada à razão culmina com a visão cartesiana, que se incorporou às tradiçóes iluministas, segundo a qual a primeira maneira de evitar o erro seria tornar a infância um estado de patologia; entendendo patologia como as 'manchas' que se expandem antes do uso da razáo e que, portanto, devem ser eliminadas pelos mestres, pelos livros e pelos costumes.

O mesmo paradigma da modernidade - sob a hegemonia da racionalidade - providenciou formas de ruptura entre os saberes, estabelecendo distinção entre os campos da racionalidade das ciências, da ética, da moral e o da estética ou expressões artísticas.

Assim, na educação dos pequenos, normalmente vinculada à família e à escola, tornou-se fundamental investir, prioritariamente, nos aspectos do desenvolvimento do conhecimento de áreas da ciência e da orientaçáo ética e moral. Nesse contexto, uma convocação é feita à literatura: cooperar com a família e a escola em razão de seu poder de sedução; mas, ao mesmo tempo, lhe é usurpado o direito à ludicidade e à polissemia, próprias do objeto artístico, tornando-se uma espécie de ficção preparada para mascarar o real, ou seja, para desenhar uma pretensa realidade homogênea e orientada por princípios da ordem para o progresso.

A evidência desse modelo que persegue o veraz e o didático, em lugar do ficcional e do verossímil, emerge com narrativas presas a uma descrição geográfica dos espaços, com realismo da situação ambiental, com a busca de um tempo absolutamente cronológico, com a exatidáo do tempo linear da narrativa, com relaçóes de causa e consequência entre as ações, com a força do discurso autoritário e monológico do narrador, com observação exata e com a predominância da referencialidade da mensagem.

As Fábulas (1668), de La Fontaine; Os Contos de Mamãe Gansa (1691/1697), de Charles Pierrault; Telêmaco (1699), de Fenelon, os contos 
de fadas, os contos maravilhosos recolhidos pelos Grimm, os escritos por Andersen, entre outros, são considerados os livros pioneiros do mundo literário infantil e constroem-se em diálogos com textos da antiguidade, perpetuandose por meio das narrativas orais. São narrativas que permanecem vivas, ora pelo caráter premonitório, ora pelos valores universais - morte, vida, sexo, sobrevivência, fome, poder -, que estão inscritos no avesso desse tecido textual, ora pela ambiguidade, ambivalência, indeterminação temporal e magia que os caracteriza. Sob o selo da razão, no entanto, transfiguram-se os caracteres: literário, lúdico, erótico e mágico dessa literatura.

A descoberta da criança, como ser diferenciado do adulto, em conformação com o desenvolvimento da ideologia burguesa, da formação da família unicelular, marca, para alguns estudiosos, o inicio da literatura infantil. Imbricada nas relaçôes de instrução e formação da personalidade, da moral, da inteligência, do raciocínio e intelectualidade das crianças e dos jovens, sob o paradigma da modernidade, a literatura submete-se, também, a equívocos que derivam da descoberta da especificidade da infância.

Nelly Novaes Coelho (2000) questiona se é ainda possível manter essa ideia. Para a pesquisadora, a literatura infantil ocupa um lugar específico no âmbito do gênero ficção, visto que ela se destina a um leitor especial, a seres em formação, a seres que estão passando pelo processo de aprendizagem inicial da vida. Daí, o caráter pedagógico inerente à sua matéria. Mas, acima de tudo, assevera, é necessário considerar o seu caráter lúdico. Para autora, "aquilo que não diverte, desafia intelectualmente, emociona, interessa ao pequeno leitor, não transmitirá, também, nenhuma experiência educacional fecunda" (COELHO, 2000, p. 164).

No momento atual da história humana, tornou-se evidente que se vive entre um sistema herdado da civilização ocidental racionalista, progressista/ cristã, cujos valores de base já se deterioraram, e uma nova dinâmica cultural em processo de construção, que, cada vez com mais força, vem se impondo ao homem, às ciências e às artes. $\mathrm{O}$ ser humano, hoje, encontra-se em uma fase de transição paradigmática, fala-se em crise da educação, em constantes metamorfoses da literatura que se rearticula com as modificaçóes da realidade mutante. Com efeito, estamos sentindo os abalos sistêmicos ou, como diz Nelly Novaes Coelho (2000), estamos no olho do furacáo.

Os paradigmas emergentes anunciam a complexidade e a imprevisibilidade das relações e dos fenômenos. Assim, enfrentar o imprevisto, negociar com o 
inesperado é assumir uma nova racionalidade crítica e intensificar a vontade de realizar nossa cidadania na Terra neste século XXI.

Se até o século XX, o homem foi definido de uma maneira unilateral e bipolarizada, como: sapiens - pela racionalidade; como faber - pela técnica; como economicus - pelas atividades utilitárias; e como prosaicus - pelas necessidades obrigatórias.

O século XXI anunciará o homem complexo: "sapiens (sábio) e demens (louco); faber e ludens (trabalhador e lúdico); empiricus e imaginarius (empírico e imaginário); economicus e consumans (econômico e consumista); prosaicus e poeticus (prosaico e poético)". (MORIN, 2003, p. 58).

Portanto, refletir, neste momento de nossa história, acerca de literatura e educação, é refletir acerca do redimensionar das experiências humanas na transiçáo de paradigmas, o que requer, seguramente, um olhar atento para as formas como essas áreas se manifestam e se correlacionam nesse contexto.

\section{Literatura e educação: o tecer de paradigmas}

Um paradigma ${ }^{1}$ constitui-se como uma lógica organizadora composta por conceitos ideologicamente selecionados, com os quais se lê o mundo e nele se atua. Portanto, subterrâneo e, ao mesmo tempo, soberano, o paradigma organiza e controla o pensar, o sentir e o querer do homem.

A modernidade configurou-se, assim, sob o signo da razão - o ponto de partida e a certeza última - o que asseverava ao homem a capacidade de conhecer, cada vez mais e com muita precisão, a natureza. A equação seria precisão, experimentação, previsão = eficiência. Pelas leis da natureza, qualquer sistema que tivesse suas condiçóes iniciais determinadas, poderia ter sua evolução exatamente prevista, não havendo lugar para o erro e nem para o mistério. De posse do conhecimento, era possível testar e prever. Ponto que leva Descartes a traçar uma história do futuro. Esse paradigma das certezas esconde a complexidade dos fenômenos e das relaçóes.

A edificação desse sistema subjaz à organização da escola e de seus princípios educacionais, à concepção moderna de infância e também permeia e orienta parte da produção literária para crianças e jovens, balizando as compreensóes das categorias do imaginário como o jogo, o maravilhoso, o fantástico e o insólito. 
Hoje, cada vez mais, torna-se evidente não ser possível acreditar em uma moldura teórica monolítica, à qual se possa apelar para determinar a natureza do conhecimento e, por conseguinte, da educação - atividade responsável pela inserção do indivíduo no tríplice universo da cultura, do trabalho e das atividades simbólicas de uma determinada sociedade. São diversas as hipóteses explicativas que surgem, há a adoção de posturas relativistas, pluralistas - ou a recusa de escolha.

Nossa posição é intermediária. Partimos do pressuposto de o ser humano ter uma natureza eminentemente falível, o que nos leva a negar o dogmatismo; e, ao mesmo tempo, ter a humildade de reconhecer que toda e qualquer interpretação singular é sempre incompleta e falível. E é exatamente a consciência dessa falibilidade que nos mune de energia e empenho para a análise do objeto de estudo, para o conhecimento dos conceitos e sua operacionalidade. É o que nos conduz a um estado de alerta, disponibilidade, rigor na investigação e nos move a também nos despojarmos de crenças, quando a experiência estiver contra elas.

Dessa forma, o conhecimento é infinitamente aproximativo, a verdade sob mira é uma verdade movente e não a-histórica. A noção de verdade vincula-se a uma comunidade de investigadores como um ideal regulador.

Enquanto humanos, somos dotados de uma fascinante capacidade de criar simulacros e com eles aprender, tornando a aprendizagem mais célere e o conhecimento virtual. Farejamos a verdade, mas aprendemos com o "erro" exatamente para exercitar a propriedade autocorretiva da razão, como nos ensina Peirce (1990). É talvez para que esse exercício seja efetivo, que o homem é um animal cuja infância é tão prolongada, não podendo ser mais considerada, como queria Descartes, a fonte de enganos.

A infância, portanto, constitui o exercício de um instinto pela verdade, o qual exige um trânsito entre o sensível, o inteligível, o imaginativo e a ação, para o necessário desenvolvimento do autocontrole-crítico. Esse autocontrole-crítico não é manipulação instrumental, "mas crítica reflexiva que pode ser fomentada com uma comunidade autocrítica de investigadores". (BERNSTEIN, 1990, p. 198).

A razão, nessa perspectiva, move-se por meio de inferências lógicas, entre as quais se encontra a abdução, força meiga de uma razão aventureira - motor lógico do raciocínio - e também da transgressão, da ruptura, ou melhor, da 
possibilidade de perceber novos mundos a serem desvendados. A essência da razão, assim, é um estado processual e de crescimento. É exato o que leva a ciência a ser concebida como algo vivo. Assim, o mistério e a indeterminação fazem parte do objeto e do processo de investigação.

A educação, desse ponto de vista, só pode ter um aspecto dinâmico, dialético e mutável, engendrando-se nas constantes formas de adaptação desse homem híbrido, mutante e complexus, como define Morin (2003).

Ao fim e ao cabo, a singularidade dessas ideias, a nosso ver, está na compreensão de que Arte e Ciência compactuam no exercício da razão; de que a experiência estética é também uma forma importante de investigação, sugerindo novas possibilidades de compreensão do real e questionamento da própria realidade.

Desse modo, a estética pode ser concebida em bases muito diferentes das que serviram de apoio às tradicionais estéticas filosóficas, como a beleza e o prazer. Constitui uma ciência e não se resume à ciência do belo, mas investiga e indaga fenômenos ou estados de coisas que de algum modo são dignos de admiração ou repulsão. Assim, deve estar na mira da educação, bem como, devem estar as suas atualizaçôes privilegiadas que são os objetos artísticos, entre eles a literatura.

Se compreendermos a literatura como "um autêntico e complexo exercício de vida, que se realiza com e na linguagem" (COELHO, 2000, p. 24), ou como um universo sensível aberto às reflexóes da vida e da história, ou ainda como um fenômeno de linguagem resultante da experiência social, política e cultural do homem, pode-se vislumbrar um terreno fértil para semeadura de uma nova forma de estar no mundo e de compreender a aventura humana também em face dos novos desafios que estão postos neste milênio.

\section{Literatura infantil e juvenil contemporânea e possíveis interfaces com a educação}

A literatura híbrida (informativa, ficcional, crítica, reflexiva, dialógica e lúdica) inaugurada por Monteiro Lobato, vem sendo enriquecida com a contribuição de novos escritores. Uma nova consciência de linguagem, da materialidade do signo artístico manifestou-se na literatura infantil e juvenil a partir dos anos 1970, consolidou vetores muito expressivos da criação literária, 
dentre os quais a intertextualidade, metalinguagem, confluência de códigos, resgate de formas, de problemáticas, diálogos entre palavra e imagem em produçóes que se constroem questionando ou explicitando o próprio processo de sua construção e convocando o leitor a assumir um posicionamento menos ingênuo nos atos de leitura e fruição.

A desmontagem dos elementos da obra, para detectar processos de produção a faz ganhar dimensão mais dinâmica, uma vez que nela ficam franqueados elementos que presidem sua gênese, os diálogos e transformaçôes. A recepção, por sua vez, também, se torna mais dinâmica, pois modifica, de forma constante, a leitura desses processos, desvelando as formas de linguagem de que se reveste a realidade.

Os recursos ficcionais promovem uma produção textual que se faz como tecido urdido com fios de realidade e ficção, como jogos de linguagens na configuração do objeto literário a ser disponibilizado para crianças e jovens como se estivessem preparando seus leitores para as próximas metamorfoses que vão ocorrer com a inserção de novas tecnologias na produção, recepção e consumo, pela interface das linguagens verbais, visuais e sonoras, pelo estreitamento do tempo e espaço ao homem em face do desenvolvimento das telecomunicaçôes - motivações que se associam a outras de caráter cultural como: a consciência de uma complexidade cada vez maior do pensamento e da vida, e a descoberta do comportamento instável e caótico do universo. Essa constituição diagramática reflete e refrata a complexidade, ora vigente no mundo contemporâneo, em que a multiplicidade e a imprevisibilidade aparecem como dados a serem decodificados, exigindo do homem encarar-se em um universo como obra em movimento.

Em um cenário como esse, escolhemos, no conjunto de produçóes literárias para crianças e jovens, uma obra, entre outras, em que a decodificação poética da realidade contemporânea revela-se como um modelo gerador de um estilo de vida e ao mesmo tempo constrói-se como "uma estética do desassossego", "da instabilidade". Trata-se de $O$ personagem encalhado, livro de autoria de Angela Lago (2006). Um projeto bem sucedido do experimentalismo artístico, tecnológico que motivou o crescente mercado e investimento na área da literatura infantil. Projeto que inclui densa consciência de linguagem a que chega a literatura para crianças e jovens, fazendo o livro ultrapassar a mera condição de portador de histórias para crianças, sua própria materialidade participa do construto narrativo, do processo da criação, revelando-o em metalinguagem, 
dando vigor ao jogo literário em suas múltiplas faces de leitura, dimensionando a posição da critica literária e dos processos de formaçáo de leitores literários. A composição propóe uma espécie de analogia com o modus vivendi de nossa era. A produção engendra-se por uma estética na qual predomina a sensação desestruturante de desgoverno das expectativas. Embora de forma lúdica, traçam-se caminhos em que tudo se torna precário. Um sentimento do provisório, do frágil, do especulativo, a incerteza se torna pano de fundo que preside as açōes.

Figura 1 - O personagem encalhado (folha dupla)
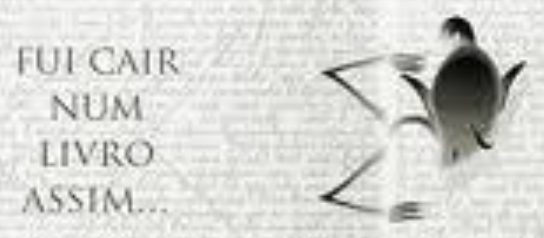

Fonte: O Personagem Encalhado - HRJ, Angela Lago, 2006.

O Personagem Encalhado (figura 1) - nomeado pelo título - é um estranho protagonista. Ele próprio tece a narrativa com seu depoimento reiterativo. Esse depoimento vai dando corpo a um manuscrito que se faz como uma rede gráfica de letras e linhas que se oferece ao leitor como uma cena, de onde o personagem emerge, gesticula, procura liberdade, mas na qual está preso. Os sentidos do verbal podem ser recuperados por uma leitura que procure articulaçôes entre rasuras, lacunas, reticências, pausas. Ao fim e ao cabo, tem-se a singularidade do fazer literatura e a criação de espaços ficcionais. Resumidamente, diz-se ali - aquilo que se está lendo é e não é o que se está lendo. Lembrando Borges, em um ensaio denominado Magias parciais do Quixote:

Por que é que nos inquieta que o mapa esteja incluído no mapa? E as mil e uma noites num livro das mil e uma 
noites? Por que é que nos inquieta que Dom Quixote seja leitor do Quixote? Dom Quixote no Quixote lê o Quixote. E Hamlet espectador de Hamlet? Creio ter dado com a razão. Tais inversôes sugerem que os personagens de uma ficção podem ser leitores ou espectadores, nós, seus leitores ou espectadores, podemos ser fictícios. (BORGES, 2007, p. 86).

É Angela Lago (2006) quem traz, aqui, um desses jogos prediletos de Borges: a interpenetração ficção/realidade. Numa atitude lúdica, demonstra que a linguagem é linguagem, o conto é uma ficção e escrever é uma atitude imaginária. Ao escrever, a escritora assume a literatura como criação, a linguagem como invenção e a ficção como jogo - jogo de identificação e oposição entre o referente imaginário do texto e o eu do leitor. Além do mais, vai desvelando como o lúdico permite à arte de mascarar-se diante do referencial, como instrumento de afirmação criadora, aberta, diante de uma realidade que pretende anular a plenitude de ser no mundo.

É a palavra o meio de esconder e revelar o universo. Desencadeando um processo de geração de interpretantes, tem-se um texto que remete a outro que remete a outro. Acentua-se o papel do leitor. Ao falar de si, metalinguisticamente, a literatura também assume e oferece uma nova visão de mundo, complexa - e o leitor é convocado a participar, pois sua leitura passa a ser uma escritura. Ao tomar consciência do processo criador, o leitor é chamado, porque o prazer de ler está no desafio de desvelar o processo de escritura.

O labiríntico e plural universo artístico de Angela Lago, em seu conjunto, faz com que coexistam fontes heteróclitas submetidas a um tratamento estético, à ordem do imaginário, em maravilhosa capacidade combinatória. Daí, a autora, em diversas obras, utilizar-se da plasticidade da escrita e, inclusive, de rasuras como pistas metodológicas do tecer da trama textual, como é o caso de $O$ Personagem Encalhado (LAGO, 2006). Pistas capazes de apontar para o simulacro de princípios adotados pelo escritor na tessitura escritural. Rasuras como índice do diálogo do criador com ele mesmo, que se manifesta na palavra refletida no tempo e concretizada no espaço, numa relação sensível do pensamento com a matéria prima.

A voz do narrador é problemática, figura-se em uma consciência artística que se expressa na enunciação e em uma alteridade que rompe estereótipos, ao imbricar valores que advém de campos ideológicos distintos (personagem 
encalhado e escritor - no nível diegético, entre personagem e autor implícito, no nível de enunciação e a própria obra que protagoniza o conflito). A voz da personagem solitária ecoa no leitor um tom solidário, devido a articulaçóes contra ideológicas que reverberam.

A personagem, por sua vez, quer autonomia - reclama - tem densidade. Mexe nas palavras, como se pode conferir, intervém na estória, como se providenciasse o "E", confirmando o encalhe. A personagem é figura viva. Sobressai-se, mas está presa. Os contrastes do fundo com o primeiro plano transformam o sistema codificado em qualidade metafórica. Imagem. $\mathrm{O}$ fundo pode não ser lido. Mas, quando o é, estabelece um vínculo com o leitor, chama-o para o debate. Inclui o leitor no percurso da personagem, no indefinido, num ambiente frio, acinzentado; novamente o contraste da letra cursiva (tipográfico cursivo) imprime afetividade e emoção ao texto em cores frias. $\mathrm{O}$ conflito do escritor/personagem possui uma temporalidade indefinida. $\mathrm{O}$ leitor torna-se co-personagem e o escritor, em sua leitura, releitura, passa a dividir o papel com o leitor, também autor.

O título da obra, O Personagem Encalhado, propóe um jogo lúdico, amalgamando signos icônicos e simbólicos. $\mathrm{O}$ texto é a própria persona em ação. $\mathrm{O}$ escritor/leitor se faz na tensão entre criar e ser criado pelo personagem, no conflito criador/criatura. Perde-se a noção de autoria, como se o texto passasse a ser autônomo, adquirindo vida própria. Metalinguagem da metalinguagem.

Exemplifica, metaforicamente: "naufrágio" - nau frágil. A personagem cujo pé fica preso no grampo/costura movimenta-se, embaraçado em seu próprio habitat, subjugado ao próprio espaço de criação, gesticula e fala, o tempo todo dentro do livro. Ao perceber a tarja preta, na capa, como uma fita adesiva remendando o livro, é possível inferir que o personagem desfolhou o livro e que este foi restaurado pelo autor que a ele volta, pelo leitor que o possui, aquele mesmo que o reconstruiu. Evidentemente, sem compactuar com o autor desta ideia de ficcionalidade - ou não perceber que o que se está lendo ocupa um espaço ficcional - é impossível a percepção da complexidade, bem como o do lúdico da literatura e da arte.

As obras atuais, em sua maioria, são assim arquitetadas, a lógica estrutural desfaz-se e o caos brota à margem da ordem. São compostas de textos em fragmentos ligados por elos probabilísticos, criando espaço de potencialidades dos sujeitos que as integram (leitor e autor), e dos componentes de significação que entram em sua discursivização. Intercambiando sentidos, desafiam as 
interpretações lineares, permitindo, em cada entrecruzamento de sentidos, adensar-se o caráter revelador.

Com essas convivem uma produção artística e intelectual disseminada em redes hipermidiáticas, de computadores que vem introduzindo novos elementos à imaginação criadora, ao pensamento investigativo e à indagação estética que se opera em nosso tempo.

O digital substituiu o analógico na gravação e transmissão, modificando radicalmente a relação entre representação e espaço. As formas de representação passam a ser niveladas à manipulação algorítima do código digital, o espaço torna-se abstrato. Referência e designação perderam a centralidade, daí a relação modelo e cópia perder a importância. A rigorosa separação entre palavra e imagem e a subordinação desta àquela são abolidas. Como sinaliza Foucault (2005), ao comentar Magritte, a imagem não mais ilustra o texto, nem o texto comenta a imagem; são formas hibridas que constroem as fronteiras do visível e do dizível. Os modos de expressão podem ser apropriados e submetidos a transformações criativas ou deformações irônicas. As noções de prestígio e autoridade autoral estão abaladas, abrindo possibilidades de criaçóes coletivas.

Verifica-se que o universo textual se modificou, a espacialidade multifacetada e heterogênea trouxe à baila uma noção de tempo não linear e descontínuo, com múltiplos centros abertos à intervenção de leitura. Esses elementos já são trabalhados na obra impressa de Angela Lago (2006), como foi possível observar, desafiando o leitor imersivo, esse leitor próprio da cultura digital.

Novas respostas perceptivo-cognitivas, seguramente, são dadas em face do hibridismo promovido pelas novas criaçóes, afinal, há outras atividades implicadas no ato de leitura e nos processos de aprendizagem. Estamos, portanto, diante da necessidade de compreensão das transformações dinâmicas que ocorrem historicamente para que sejam possíveis formas menos anacrônicas de atuar no universo da educação.

Nessa ordem de ideias, vale lembrar ainda, que cada sociedade, em diferentes épocas, também produziu modos diferentes de leituras e fez emergir diferentes leitores. Se o leitor próprio do iluminismo tinha diante de si textos duráveis (livros), que podiam ser revisitados a todo e qualquer momento, é importante lembrar as diferenças que se impóem entre esse e o leitor fruto da revolução industrial, do desenvolvimento do capitalismo, o qual recebe grande 
apelo de informaçóes simultâneas, desafiado à decifração de textos híbridos em diferentes suportes. Hoje, estamos diante da inevitável emergência de um leitor imersivo - aquele que, diante do texto eletrônico, navega programando leituras, num universo de signos evanescentes e disponíveis. Esse leitor passa a conviver com o leitor do livro, meditativo, e com o leitor movente, leitor de formas, volumes, massas e movimentos. Temos, hoje, leitores múltiplos e, ao mesmo tempo, um leitor híbrido. Ressalte-se que a atividade leitora é uma forma de aprendizagem complexa, não cabe nos limites deste trabalho desenvolver o assunto, mas vale considerar as formas como as crianças, em ambientes virtuais, processam suas atividades perceptivas e cognitivas em espaços de comutação que permitem trânsito informacional, onde há possibilidade de serem negociadores de sentidos, em um fluxo de signos que surgem e desaparecem em função do acesso e das comunicaçóes.

Tendo a tela do computador como suporte em linguagem da hipermídia, circulam em redes interplanetárias: poemas, lengas, narrativas revisitadas. Hoje, orquestram-se vozes múltiplas, com potencial polifônico. As personagens são figuras sintéticas com animação. Suas ações dependem do cursor, do mouse do internauta e do movimento interno ao programa de computação. O verbal - oral e escrito -, apesar de sua dominância simbólica, adquire a função de ícone de navegação. $\mathrm{O}$ som manifesto na linguagem oral permite atestar, nas inflexôes de voz, o caráter de linguagem híbrida. As vozes se sobrepóem em camadas diversas - algo que vai evidenciando o potencial e o limite do aparato humano e revelando recursos possíveis da mídia tecnológica. Sons simultâneos criam planos sonoros, em montagem por sobreposição e justaposição de vozes, timbres diferenciados - fazendo com que a esfera do som deixe de ser apenas percebida no tempo, ao longo da duração, linearmente, para engendrar um espaço acústico e mental - o que estaria na base de composição dos experimentos poéticos de text-sound.

No escopo e temática da literatura infantil e juvenil do $3^{\circ}$ milênio, encontram-se questóes relevantes para a sociedade atual, como relaçóes raciais, a questão do feminino, a homossexualidade, a marginalidade, as diferentes formas de organização familiar, a prostituição infantil, envolvendo de forma crítica questôes que estão permeando a sociedade. Tais problemáticas, quando legitimadas por um olhar de fronteira e inseridas com propriedade literária no universo ficcional, tornam-se partícipes de um aspecto educacional mais amplo, o exercício da alteridade. 
Para os educadores e críticos literários Gardin e Oliveira (1981), educar não poderia mais ter uma direção única, e tampouco poderia ocorrer por meio de métodos de autoridade sustentados por modas ou crenças dominantes. $\mathrm{Na}$ verdade, essas são as tristes sendas em que se assentam ainda grande parte das práticas pedagógicas e o caminho da Educação, enquanto aparelho ideológico do Estado.

Concordamos com os autores, pois a práxis educativa deveria atuar desde as esferas mais sutis do desenvolvimento das qualidades do sentir, àquelas da luta pela sobrevivência, até as mais elevadas formas criticas e reflexivas de elaboração mental de intenções prospectivas. Isto implica em outra dimensão do ato educativo, uma vez que desse modo, estaríamos diante da necessidade de educar, em um sentido amplo, que constituiria em um processo complexo de sempre recomeçar. Nesses termos, a função educativa implicaria introduzir cada ser, através da história de sua experiência, na sintonia com o ritmo da realidade - com o ritmo "caleidoscópico e originário da realidade", e colocar o educando de prontidáo "para aprender a vastidão daquilo que não se sabe" (GARDIN; OLIVEIRA, 1981, p. 46). E seguramente, pode-se conceber a arte literária como um caminho para esse aprendizado.

\section{Consideracões finais}

Não se pode negar que vivemos um momento um tanto delicado da história, em que transformaçóes culturais profundas têm inserido o homem em um angustiante estado de desordem. É bastante discutida a ideia de que o caos, compreendido como informação complexa, traz em seu seio uma nova ordem.

Nessa ordem de ideias, um faro investigativo para a tessitura de novos paradigmas encontrar-se-ia nas interfaces criadas entre a ciência, a arte e a tecnologia. A literatura, arte que as engendra, para nós, é um fio de Ariadne no labirinto dos novos tempos.

Compreendemos que a literatura para crianças, na atualidade, tem se revelado como um espaço para o qual confluem múltiplas possibilidades de linguagens e diferentes sistemas narrativos. Para essa complexa e desafiadora paisagem cabe um olhar atento dos novos pesquisadores. Por ser fenômeno de linguagem, sua configuração necessita ser vislumbrada pelo prisma da história, da cultura, do seu contexto de produção, da sociedade em que se inserem autores, leitores, suportes, códigos e linguagens. 
Constamos que as novas geraçóes vivenciam a mudança paradigmática de uma maneira bastante intensa - motivo pelo qual a Educaçáo náo pode se distanciar dos questionamentos e dos estudos que envolvem as consequências dessas tão rápidas transformaçôes. Distintas marcas históricas singularizam as formas artísticas, as várias migraçóes e reinvençôes de imagens, de concepções e estruturas que se afirmam como metáforas para formulação de conceitos estéticos e modos de conhecimento da realidade.

A literatura, seguramente, configura-se essencial para que se manifestem modos mais críticos de acesso ao conhecimento do real e para a adoção de uma práxis que acene para possibilidades de transformação da sociedade e do mundo. Portanto, entendemos, é nesse aspecto que a literatura infantil e a educação poderiam se tornar aliadas.

\section{Notas}

1 Para Morin (2003), um paradigma efetua a seleção e a determinação das operaçóes lógicas, Designa as categorias fundamentais da inteligibilidade e opera o controle de seu emprego. Assim, os indivíduos conhecem, pensam e agem segundo paradigmas inscritos culturalmente neles.

\section{REFERÊNCIAS}

ARIÈS, Philippe. Historia social da criança e da família. Rio de Janeiro: Guanabara, 1981.

BERNSTEIN, Richard J. A sedução do ideal. Face: revista de semiótica e comunicação, São Paulo, v. 3, n. 2, jul./dez. 1990.

BORGES, Jorge Luis. Outras Inquisições. São Paulo: Companhia da Letras, 2007.

COELHO, Nelly Novaes. Literatura: arte, conhecimento e vida. São Paulo: Peirópolis, 2000.

FOUCALT, Michel. As palavras e as coisas. Lisboa: Edições 70, 2005.

GARDIN, Carlos; OLIVEIRA, Maria Rosa. Semiótica e Educação. Arte e Linguagem: Língua e Literatura na educação. Sáo Paulo: Educ, 1981. (Cadernos PUC, n. 14). 
LAGO, Angela. O personagem encalhado. Belo Horizonte: RHJ, 2006.

MORIN, Edgar. Educar na era planetária: o pensamento complexo como método de aprendizagem no erro e na incerteza humana. São Paulo: Cortez, 2003.

PEIRCE, Charles Sanders. Semiótica. São Paulo: Perspectiva, 1990. 


\section{Barcos frágiles y nuevos paradigmas en la literatura y en la educación}

\section{Resumen}

El siglo XX presenció la ruptura de las referencias que anclaban el mundo social, la transición paradigmática exigió otra mirada en temas relacionados con el hombre, la sociedad, la ciencia y el arte. Desde esta perspectiva nos acercamos a nuestro objetivo: reflexionar sobre la Literatura Infantil como un fenómeno que se constituye en la tensión dialéctica - Literatura/Educación. El artículo se centra en dos momentos de la historia occidental: la asociación de la literatura para el proceso educativo, con la inscripción de los niños en la sociedad; la contemporaneidad, una época en que la literatura infantil, consolidada, vigoriza el juego en múltiples facetas de la lectura, rediseńando los procesos de formación de lectores. Las articulaciones manifiestas son la síntesis de años en la enseñanza y la investigación en la Universidad de San Pablo - USP SP en Estudios Comparados y Literatura de la Infancia y la Juventud. Proceso de investigaciones profundizadas en la maestría y en los estudios de doctorado acerca de la formación del pensamiento moderno, la dinámica de la construcción de conceptos que generan la praxis educativa. Estas rápidas transformaciones, motivaron lecturas, entre ellas, el problema de la escuela, debido a un nuevo lector que trabaja con múltiples códigos, lenguajes y con claro acceso a las cuestiones sociales. Las nuevas

\section{Fragile ships: new paradigms in literature and education Abstract}

The 20th century witnessed a break with the references that anchored the social world. This paradigmatic transition demanded a reconsideration of the issues related to man, society, science and art. The objective of this study is traced from this perspective: to reflect on children's literature as a phenomenon that is constituted in the dialectical tension between literature and education. We focus on two moments in the history of Western civilization: that of the association of literature to the educational process, and the inscription of the child in society and the contemporary world, a time in which children's literature reinvigorates the literary interplay, redimensioning processes of educating young readers. The articulations presented here are syntheses of the path of teaching and research conducted at the University of São Paulo in the field of Comparative Studies and Literature for Children and Young People. The research was part of our master's and doctorate studies on the formation of modern thinking, the dynamic of the construction of concepts that compose educational praxis and the swift transformations that motivate rereadings. These include the problem raised for schools by new readers who conduct reading amid an interflow of virtual networks, with multiple codes, languages and free access to the complexity of social issues. The new generations experience 
generaciones experimentan el cambio de paradigma intensamente, por lo que la educación no puede distanciarse de las cuestiones que afectan a los cambios rápidos. El análisis de la obra de Angela Lago (2006) muestra cómo creativamente la literatura contemporánea para niños y jóvenes refleja la complejidad que vivimos, lo que constituye un fuerte aliado de la educación para el acceso al conocimiento y la posibilidad real de adoptar una praxis más crítica.

Palabras claves: Paradigma. Educación.

Literatura infantil y juvenil.

\section{Maria Zilda da Cunha}

E-mail: mariazildacunha@hotmail.com the paradigmatic change intensely, for which reason education cannot remain distant from the questionings that involve these rapid transformations. We use the work of Angela Lago (2006) to indicate how contemporary literature for children and youth creatively reflects the complexity in which we live, constituting a strong ally to education for accessing knowledge of reality and the possibility for adopting a more critical praxis.

Keywords: Paradigm. Education. Children's literature.

Recebido em: 12/3/2012

Versáo final recebida em: 13/12/2012

Aprovado em: 21/12/2012 